\title{
Dual Effects of Partner's Competence: Resource Interdependence in Cooperative Learning at Elementary School
}

\author{
Céline Buchs ${ }^{1, *(\mathbb{C}}$, Anissa Dumesnil ${ }^{2}\left(\mathbb{D}\right.$, Julien Chanal ${ }^{3,4}\left(\mathbb{C}\right.$ and Fabrizio Butera ${ }^{5}(\mathbb{C})$ \\ 1 Department of Educational Sciences, University of Geneva, CH-1211 Geneva, Switzerland \\ 2 Department of Educational Sciences, LaRAC, University of Grenoble Alpes, 38400 Grenoble, France; \\ Anissa.Dumesnil@univ-grenoble-alpes.fr \\ 3 Department of Psychology, University of Geneva, CH-1211 Geneva, Switzerland; Julien.Chanal@unige.ch \\ 4 Distance Learning University, 3900 Brig, Switzerland \\ 5 Social Psychology Laboratory (UNILaPS), Institute of Psychology, University of Lausanne, \\ CH-1015 Lausanne, Switzerland; Fabrizio.Butera@unil.ch \\ * Correspondence: Celine.Buchs@unige.ch; Tel.: +41-22-379-90-36
}

Citation: Buchs, C.; Dumesnil, A.; Chanal, J.; Butera, F. Dual Effects of Partner's Competence: Resource Interdependence in Cooperative Learning at Elementary School. Educ Sci. 2021, 11, 210. https://doi.org/ 10.3390/educsci11050210

Academic Editor: Robyn M. Gillies

Received: 29 March 2021

Accepted: 23 April 2021

Published: 29 April 2021

Publisher's Note: MDPI stays neutral with regard to jurisdictional claims in published maps and institutional affiliations.

Copyright: (c) 2021 by the authors. Licensee MDPI, Basel, Switzerland. This article is an open access article distributed under the terms and conditions of the Creative Commons Attribution (CC BY) license (https:/ / creativecommons.org/licenses/by/ $4.0 /)$.

\begin{abstract}
A partner's competence should logically favor cooperative learning. However, research in cooperative learning has shown that a partner's competence may or may not activate a threatening social comparison and yields dual effects: It is beneficial when students work on complementary information while it is detrimental when students work on identical information. Two studies conducted at elementary school (study 1 with 24 fourth graders working on encyclopedic texts, and study 2 with 28 fifth graders working on argumentative texts) replicated that interaction: Information distribution (complementary vs. identical information) moderated the relationship between partner's competence and pupils' learning outcomes. The relation between partner's competence and students' performances was positive when working on complementary information, but negative when working on identical information. A third study confirmed that working on identical information led to a competitive social comparison whereas complementary information reinforced the pupils' cooperation perception. Contributions to cooperative learning research are discussed in terms of the competitive comparisons that may arise during cooperative learning at elementary school.
\end{abstract}

Keywords: social comparison; cooperative learning; resource interdependence; competence; elementary school

\section{Introduction}

Peer learning is encouraged by many instructional models in a variety of educational settings [1] from elementary school [2-6], through to secondary school [7-9], post-secondary school, and university [10-13]. Peer learning favors both work and play relations through a positive cognitive and social impact [14]. Among the peer learning methods, cooperative learning has been widely investigated due to its strong interconnections between theory, research, and practice [15-21]. Research that has compared cooperative learning with individual or competitive learning has consistently shown positive effects for a wide range of outcomes including learning (see [22] for a review of meta analyses).

Nevertheless, cooperative learning does not automatically lead to improved learning. The educational system, notwithstanding its formative mission, is fundamentally competitive [23,24], especially in the neo-liberal ideology in which most Western societies and educational institutions are embedded [25,26], and it is possible that this competitive atmosphere interferes with the effects of cooperative learning [27,28]. Indeed, a line of research carried out with university students has shown that focus on social comparison with a partner during cooperative learning may lead to a dual effect of partner's competence [29]. In this context, partner's competence can reduce as well as increase learning outcomes [30]. As competitive goals permeate the whole educational system, the aim of 
the present research is to test that such a dual effect of partner's competence in cooperative learning also emerges at the level of elementary school.

\section{Theoretical Framework}

\subsection{Cooperative Learning in a Competitive Society}

Cooperative learning proposes that students work together to accomplish shared learning goals, and has been derived into a variety of methods [31]. One key factor consensually recognized as beneficial for cooperative learning is positive goal interdependence [18,32,33], in other words, the process whereby students perceive that they can reach their goal only if the other partners reach their own [34,35]. Perceived positive interdependence motivates students to learn, encourages partners to interact with each other in a constructive manner, and effectively helps them learn $[19,35]$. This is why in mastery-based contexts in general, and in cooperative learning settings in particular, partners are generally viewed as sources of informational support likely to contribute to one's own learning [36,37].

Despite an overall positive effect, however, cooperative learning efficacy varies across studies. The effect size revealed in meta-analyses varies from moderate to large (and Hattie's mega-analysis [22] reports effect sizes between 0.41 and 0.54), indicating that cooperative learning is a potentially powerful tool for learning in comparison with individual or competitive learning. Nevertheless, reviews only report between $53 \%$ [38] to $63 \%$ [39] of comparisons, indicating positive gains in favor of cooperative learning, which points to the question of what happens in the remaining cases.

In this article, we conceptualize cooperative learning as a powerful tool based on positive goal interdependence, but a tool that has to operate in a society increasingly based on the values of achievement, power, and competition. Kasser et al. [26] has suggested that the values of what they call corporate, neoliberal capitalism, in which are embedded the majority of citizens of Western countries, may interfere with goals directed toward cooperation. This analysis echoes the work of several authors that have noted that selection, grading, and ranking typical of most educational institutions are likely to promote competitive goals [23,40-42] and to enhance performance-avoidance goals [43]. One example drawn from higher education is the selection whereby a large number of students (from 9 to $55 \%, M=31 \%$ ) enrolled at universities in OECD countries (Organization for Economic Cooperation and Development) end up without a degree [44]. The competition involved at university can also be illustrated by the European official recommendations regarding credits: For students who pass, teachers have to use normative assessment with an a priori percentage of students that should obtain different grades, namely $10 \%$ of As, $25 \%$ of Bs, $30 \%$ of Cs, $25 \%$ of Ds, and $10 \%$ of Es [45]. This grading practice hinders the willingness to cooperate with a peer [46].

\subsection{Cooperative Learning and the Dual Effect of Partner's Competence at University}

One can expect that when cooperative learning is introduced, this competitive orientation would be reduced. Nevertheless, research has pointed out that competitive social comparisons are at work, even during cooperative learning at university [29,47-49].

More specifically, in order to investigate the conditions under which competitive social comparisons are likely to interfere with cooperative learning, a line of research has studied the effects of information distribution (that is resource interdependence: resource independence versus positive resource interdependence) during cooperative learning on texts (e.g., [50]). Positive resource interdependence refers to tasks and situations in which group members possess different complementary pieces of information, each member accesses only one part of the needed information, and relies upon communication with the partners to access the rest of the necessary information. Resource independence, on the other hand, involves access to the whole information by each member, which implies that students work on identical information and do not depend on one another for information [38]. 
The study of information distribution is particularly important for the present research because working on identical information has the property of allowing members to compare and judge each other's competence. Marshall and Weinstein [51] suggested that working on simultaneous similar tasks for all students with a unique theme induces a more social comparison of abilities than working on different themes at different times. Lambiotte et al. [48] suggested that even in a cooperative context, working on identical information stresses evaluative pressure between peers compared to working with complementary information. Moreover, working with identical information altered the representation of the interaction that should be typical of cooperative learning: The mere fact of reading the same text induced students to compare themselves to the partners, which led them to question their own competence and their partner's competence [29,50]. Despite the potential positive effects of social comparison (e.g., [52,53]), when working cooperatively with identical information, this competitive social comparison was responsible for the negative effect on learning outcomes of working on identical information [29,54].

Direct comparison of competences during interactions may elicit a motivation to protect self-esteem [55], transforming the partner into a potential competitor instead of a valuable resource. This implies that the others' competence may be threatening. This supposition has been put to the test by Buchs et al. [29]. Cooperative learning produces an environment in which the competences of group members should be viewed as supportive, and logically a more competent partner should lead to better learning than a less competent partner. However, when contrasting peer-learning methods on information distribution, an interaction between perceived partner's competence and resource interdependence condition appeared, indicating that for students working on complementary information, the more they perceived their partner as competent, the better they performed, whereas the relation was negative when they worked on identical information [29]. Results have been replicated when the competence of the partner was manipulated in order to test the causal link [30]: A confederate was trained to propose either a brilliant or an average oral performance. Results indicated that the partner's competence was positive for students' learning only in the positive resource interdependence condition, whereas under resource independence, the partner's competence was paradoxically detrimental to learning. In sum, even when cooperative learning is implemented, there are conditions-such as working on identical information - under which students interpret the competence of partners as a threat to their own competence, which reduces learning. Thus, information distribution may lead to two opposite effects of partner's competence.

\subsection{A Dual Effect of Partner's Competence at Elementary School?}

As competition permeates the educational system at all levels [23], the present article thus considers the possibility of competitive social comparisons during cooperative learning, even at elementary school that could lead to the dual effect of partner's competence presented above.

\subsubsection{Social Comparison and Competition in Children}

At first glance, several elements suggest that social comparison feedback would not be used by young children to assess their intellectual ability because of the difficulty to coordinate their own and others' perspectives [56] and to make inferences regarding ability from normative information before the age of 6-8 [57]. Moreover, Stipek and Mac Iver [58] as well as Dijkstra, Kuyper, van der Werf, Buunk, and van der Zee [59] argue that pupils' attention to social comparison information as well as the need to outperform their classmates increased from the beginning to the end of elementary school and kept growing during the junior and senior high-school years. On this basis, elementary-school children could be expected to be far less prone to being threatened by social comparison than university students.

Looking more closely at the literature, however, it appears that preschoolers in natural settings display spontaneous active social comparisons [56], with a predominance of 
differentiation/similarity and competition modes of social comparison. Butler [60] noted that children may display some negative outcomes of upward comparison already at the age of three; her results and those of Rhodes and Brickman [61] indicated that children at ages three to five use others' outcomes for self-appraisal even in a non-competitive context when interpersonal comparisons are salient. Moreover, Ruble, Eisenberg, and Higgins [62] concluded that most 5-year-old children are able to infer realistic evaluations of performance and display affective reactions using concrete interpersonal comparisons. Finally, young pupils start using social comparison information to evaluate themselves from the age of seven [59]. Children are able to use differences in social outcomes to make evaluative inferences in simple contexts when they can judge the outcome difference directly [60] and to explain their self-perceptions of smartness in social comparative terms [58]. Moreover, they actively search for social comparison information [63]. For instance, pupils from grade 3 inspect and evaluate peers' work and display "besting behaviors", revealing a need to excel over others, along with comparative evaluative statements, even when the context is not a competitive one [64]. In sum, from the age of seven or eight, children become increasingly sensitive to social comparisons [65-67].

\subsubsection{Social Comparison and Competition in School Environments}

Again, at first glance one could expect that, compared with university, elementary schools are likely to favor an environment in which academic social comparison with peers is not overwhelming and threatening, as suggested by Mosatche and Bragonier [56]. Stipek and Mac Iver [58], in particular, proposed that intellectual tasks are less standardized and relative performance information less available in early years of elementary school, where normative information is not usually made salient. According to these authors, the nature of the tasks and the visibility of peer skills based on social comparison increase from early elementary (before grade 3) to upper elementary school (grades 3-6), and still increase at the middle or junior high level. This evolution is confirmed in studies that compare grades 4-5 to grades 6-7 [68], and in studies carried out at junior high school from grade 6 to 7 [69].

Relevant to this contention, achievement goal theorists have identified two separate classroom goals structures [70]; the distinction relies on the extent to which schools or classroom-level practices promote mastery goals (strong focus on understanding the classwork, efforts needed to improve learning) or performance goals (strong focus on normative evaluation and public social comparison of abilities). Elementary school appears to be more oriented toward mastery, autonomy, social and academic support, and cooperation [68,69], while focus on grades and normative comparisons increase from elementary school to middle school (see [70]). In elementary school, students are not usually assigned to classes according to their ability, special privileges offered for relative ability are less frequent, and normative evaluations are less likely.

However, data also indicate that in elementary school, social comparison is already likely to occur. Pepitone [64] underlined that being in a classroom implies a number of ingredients that reinforce the likelihood of social comparison: Novel tasks and new learning imply some degree of cognitive uncertainty, in a context where relevant others (people belonging to a reference group confronted to the same instruction) are available, and where evaluation is important. Moreover, the reward system, perceived focus on achievement and social pressure to perform well contribute to create an evaluative atmosphere in the classroom, both for children $[59,65]$ and teachers $[71,72]$. While arguing that normative evaluation is less important in elementary school than in junior high school, Stipek and Mac Iver [58] underlined that focus on relative performance, the use of competitive activities in the classroom, and assignment to classes according to ability may appear as soon as grade 3 in elementary school. The way the student perceives the teachers' goals predicts the students' performance goal pursuit [73]. As early as grade 5, some elementary teachers are perceived by their pupils as high in performance, which impacts the goal structure of their classrooms [74]. Therefore, even if social comparison is less likely at elementary 
school than at university, pupils may be sensitive to competitive social comparisons at upper elementary school (from grade 3, i.e., eight years old).

\subsection{Hypotheses and Overview}

In sum, research on the effects of information distribution at university has shown that even minor contextual cues-such as for instance working on identical information-may elicit competitive social comparison concerns during cooperative learning. In particular, as noted above, results indicate a dual effect of partner's competence: Although for students working on complementary information, the higher their partner's competence, the better they perform, when they work on identical information this relation is negative $[29,30]$.

Research also showed that social comparison may be related to competitive concernsand therefore be threatening-as early as elementary school, and the same concerns as those haunting university students may play a role at this level. Thus, drawing on research that has demonstrated that resource independence (working on identical information) triggers competitive social comparison whereas positive resource interdependence (working on complementary information) attenuates it and favors the recognition of one's partner's competence helpfulness (e.g., [50]), we predict that even with elementary school children, we should observe the same interaction between resource distribution and partner's competence on learning outcomes that was observed with university students. In a cooperative learning setting, when working on complementary information, the partner's competence should be positively linked with the pupils' learning, whereas when working on identical information, the partner's competence should be negatively linked with the pupils learning.

Two experimental studies carried out in natural settings tested this hypothesis. To provide external validity, pupils worked on encyclopedic texts in study 1 and on argumentative texts in study 2. Moreover, study 1 involved fourth graders, and study 2 involved fifth graders. The third study aimed to test the effect of information interdependence on social comparison during cooperative learning at elementary school.

\section{Study 1}

\subsection{Materials and Methods}

\subsubsection{Participants}

Twenty-four pupils, 11 boys and 13 girls, regularly attending grade 4 in a Swiss Frenchspeaking school and aged from 9.08 to 10.75 years $(M=9.87, S D=0.45)$ participated in the study. Pupils worked in cooperative dyads under the supervision of the experimenter for one session. Ten pupils worked with complementary information and 14 worked with identical information. Their regular teacher composed the dyads so that the level in French was relatively equivalent inside the dyad and that pupils could work well together (no "enemies" together).

\subsubsection{Procedure}

The experimental dyads did not work in their classroom (this applies to all three studies). Two or three dyads were brought out of the classroom at the same time; they worked in a room where they could use space in a comfortable way, without dyads interfering with each other and with a quiet environment. The experimenter requested the dyads work on two texts. Positive goal interdependence was kept constant in all conditions: Pupils were asked to work cooperatively and to try their best to promote both their own learning and their partner's learning. Their common goal was therefore to foster learning for all partners so that each learner could master the whole content [75].

Role interdependence was also constant, but roles were reversed for each text. In line with scripted cooperation procedures [76,77], two roles were introduced in order to facilitate the discussion. The summarizer role consisted of explaining as clearly as possible and in a detailed way the information contained in the text. Listeners had to ask questions, request clarifications, add comments, and identify errors or inconsistent information while 
listening to the summarizer. Roles were presented to students as flexible roles introduced in order to facilitate discussion. The terms "Summarizers" and "Listeners" thus designated the students' primary role, but did not preclude interactive exchanges. For each text, one student played the summarizer role while the partner played the listener role. Roles and text order were counterbalanced. Dyads had $12 \mathrm{~min}$ to read and $5 \mathrm{~min}$ to discuss each text. Discussions of the dyads were recorded for the purpose of analyses. After working on the texts, they filled in a learning questionnaire on the two texts.

\subsubsection{Materials}

Dyads worked on two encyclopedic texts reporting factual information: one text on ostriches and the other on chameleons. The length was quite similar (584 versus 605 words) and texts were structured in a similar way: one text (one page with nine paragraphs and eight pictures) and one figure with the explanation of some parts of the animal body (6-7 body parts). We checked that the specific content of these texts had not been addressed in the pupils' curriculum to ensure that the content was unfamiliar to them. A lexicon was used to answer vocabulary questions.

\subsubsection{Independent Variables}

- Resource interdependence: Dyads were randomly assigned to one of the two information distribution (resource interdependence) conditions. In the resource independence condition, pupils worked on identical information. Both pupils read the two texts silently and then discussed them following the assigned roles. More specifically, they both had $12 \mathrm{~min}$ to read the first text followed by a 5 -min discussion scripted by roles (summarizer and listener, cf. supra). After that, they both had $12 \mathrm{~min}$ to read the second text, and the roles were reversed for the 5-min discussion. In the positive resource interdependence condition, they worked on complementary information. Pupils read only one text and accessed the other text via the summary presented by the partner. More precisely, one pupil read the first text during the 12-min period and played the summarizer role during the discussion. In order to sustain a good level of attention from listeners when the summarizer read the text, these students were asked to draw and write all they already knew on the subject. After that, the other pupil read the second text and played the summarizer role. The texts can be considered as complementary because pupils were aware that they had to master the content of the two texts in order to answer the questions in the final individual learning questionnaire that they knew would follow the exercise.

- Partner's competence as summarizer: Summarizer's competence was assessed by counting the number of summarizers' correct informational inputs: number of main correct information (new information) + number of detailed correct explanations (when summarizers brought additional elements or more detailed information regarding a piece of information already proposed). One discussion was not taken into account because of technical problems; thus, we coded the informational input of 10 summarizers in the identical information condition and 13 summarizers in the complementary information condition. Each discussion was coded by one pre-service teacher who followed a course on social interaction in peer learning. Eight discussions were randomly selected and coded by a social psychology teacher. Coders were blind regarding the experimental conditions. The inter-rater agreement was good enough (i.e., $88 \%$ ) to keep only the pre-service teacher's coding as a measure of the summarizer's competence (from 7 to $26, M=16.83, S D=6.06$ ).

\subsubsection{Dependent Variable: Learning Outcomes as Listeners}

Individual learning was assessed with a learning questionnaire regarding each text at the end of the session composed of nine multiple-choice questions per text (one question per paragraph). The multiple-choice test (MCT) was developed by pre-service teachers and perfectly matched the normal test format used by regular teachers. Each question had 
three answers with only one being correct. One point was allocated for a correct answer, 0 for no answer and for mistakes. These criteria were explained to the pupils before the MCT. Thus, learning scores for each text ranged from 0 to 9 , and we identified the role pupils endorsed for each text to compute their performance as summarizer and as listener. This score allowed us to test the relationship between the summarizers' competence and listeners' performance, as proposed by Buchs and Butera [30]. Additional variables were measured in the three studies. As they are not relevant to the present research question, they are not reported in the text, but can be obtained by writing to the corresponding author.

\subsection{Results and Discussion}

As pupils learned in dyads, data are not independent, and therefore we conducted multilevel analyses. We built a two-level model with pupils nested in dyads. The tested model comprised our two predictors, namely resource interdependence (coded- 1 for identical information and +1 for complementary information) and summarizer's competence (assessed by the total number of correct informational inputs, centered to its mean) as well as a term for the response considered (as a summarizer or as a listener) and the interactions between these three variables.

Results revealed that the predicted interaction between resource interdependence and summarizer's competence was significant, $b=-0.20, d f=35.47, t=-2.07, p=0.05$, $R^{2}=0.13$. As illustrated in Figure 1, the relationship between the summarizer's competence and listener's learning was positive when pupils worked on complementary information $(b=0.10)$ and negative when they worked on identical information $(b=-0.09)$. As few dyads were available to test our hypothesis, we conducted the same analysis using robust modeling [78]. Results showed a unilateral $p$-value for the main interaction equal to 0.06 .

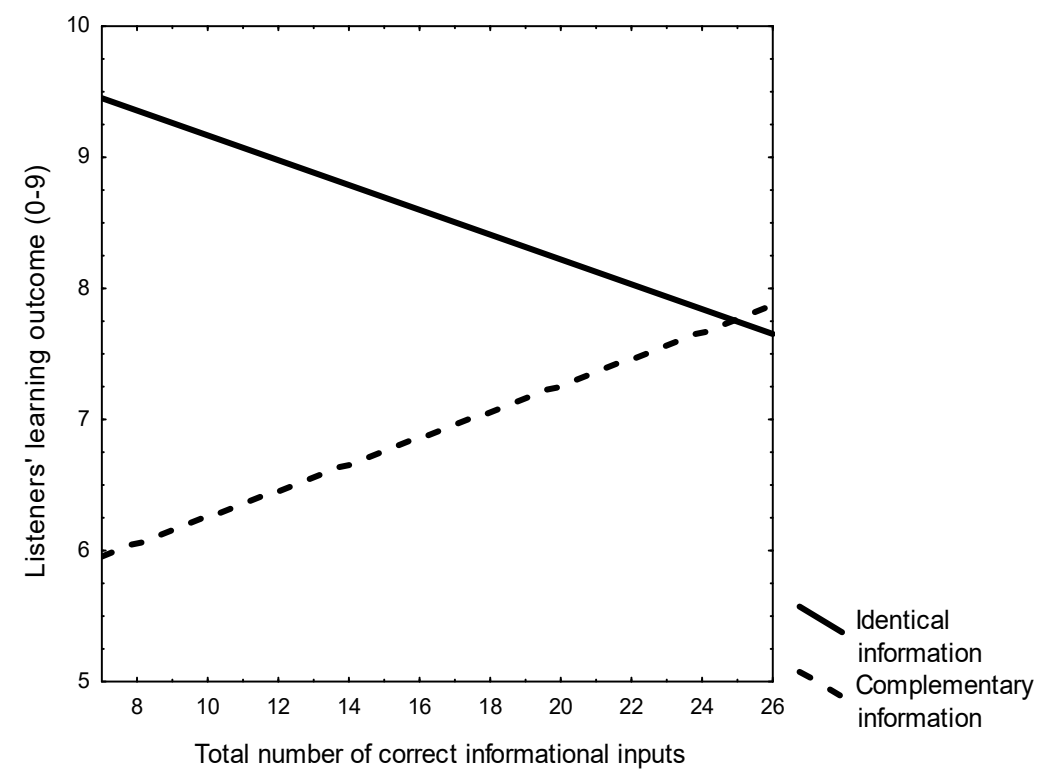

Figure 1. Relationship between the partner's competence and listeners' learning in the two interdependence conditions (study 1).

The present study, carried out with elementary school children, built upon the known properties of information distribution and showed the same pattern between information distribution and the summarizer's competence on listeners' learning as Buchs et al. [29] and Buchs and Butera [30] with university students: It indicated a positive link between the summarizer's competence and listener's learning when working on complementary information and a negative link when working on identical information.

Nevertheless, it should be noted that working on encyclopedic texts led to very little interaction between pupils. Indeed, the coding of discussions revealed that listener's 
involvement in informational exchange was rare. Of the 23 discussions, only few listeners provided an input or asked questions (including asking for some information or explanation, asking to repeat, and asked questions in order to check their understanding). More precisely, nineteen listeners brought no input at all, two proposed one informational input, one proposed three inputs and the last one proposed four inputs. Fifteen listeners asked no questions, five listeners asked only one question, one listener asked two questions, and two listeners asked three questions. As very few interactive patterns were found, we can underline that discussion on encyclopedic texts was essentially a summarizer's monologue.

In order to prompt more discussions, we proposed that students work on argumentative texts in study 2 , and we carefully chose themes that potentially interested children with the classroom teachers. Furthermore, study 2 involved older children (grade 5) in order to try to promote student interactions. Finally, carrying out a second study with fifth graders working on argumentative texts enabled external validity.

\section{Study 2}

\subsection{Materials and Methods}

\subsubsection{Participants}

As in study 1, pupils worked on dyads for one session. Twenty-eight pupils regularly attending grade 5 in two Swiss French-speaking classes, 15 boys and 13 girls, aged from 9.67 to 12.58 years $(M=10.89, S D=0.58)$ participated in the study. Teachers composed the dyads in order to obtain a relatively homogenous French level and avoid "enemies" working together. Fourteen students worked on complementary information and 14 on identical information.

\subsubsection{Procedure}

Dyads were randomly assigned to one of the two experimental conditions regarding information distribution (resource interdependence: independence vs. positive interdependence). The procedure was identical to study 1 .

\subsubsection{Materials}

In order to promote social interactions and discussion, we proposed that pupils work on argumentative texts. We looked for interesting themes for both girls and boys, and after discussion with the teachers, we chose one text on video games and another on dogs as pets. The length was quite similar: 650 words for the text on dogs versus 631 words for the text on video games. Texts were structured in the same way with five positive and five negative arguments in each text. We checked that the specific content of these texts had not been discussed previously in class. We built a lexicon in collaboration with teachers in case pupils asked vocabulary questions.

\subsubsection{Independent Variables}

As above-mentioned, pupils worked either on identical, or on complementary information with each pupil playing the summarizer's role for one text and the listener's role for the other text. Summarizer's competence was assessed by counting the number of correct informational inputs (main correct information + detailed correct explanations) proposed. A pre-service teacher who followed a course on social interaction in peer learning coded all available discussions. Moreover, a social psychologist acquainted with coding students' interactions during cooperative learning independently coded the same discussions. Both coders were blind to the experimental conditions. The correlation between the two judges was 0.94 for both the number of main correct information and number of detailed correct explanations. We computed the mean of the two evaluations to measure the summarizers' competence (from 5 to $36, M=17.52, S D=8.40$ ). 


\subsubsection{Dependent Variable: Learning Outcomes as Listeners}

Individual learning was assessed at the end of the session by a learning questionnaire for each text consisting of six multiple choice questions (one point for a correct answer and 0 for no answer and for mistakes), two fill-in-blanks questions (coded from 0 to 2 depending on the quality of the answer), and one open-ended question (coded from 0 to 3 points depending of the quality of the answer). Learning scores ranged from 0 to 13 for each text. The questionnaire was developed by pre-service teachers and approved by the two regular teachers. Three pre-service teachers coded each questionnaire, and reached an agreement for each learning outcome. Like in study 1 , we identified the role pupils endorsed for each text to compute their performance as a summarizer and as a listener in order to test the relationship between the summarizers' competence and the listeners' performance.

\subsection{Results and Discussion}

First, it should be noted that, in this study, fifth graders working on argumentative texts displayed a higher level of interaction compared to fourth graders working on encyclopedic texts (study 1). Indeed, the number of listener's questions (whenever students asked for some information or explanation, asked for repeating, asked questions in order to check their understanding) indicated that in the 27 available discussions, twenty-four listeners brought at least one informational input $(M=4.00, \max =13, S D=3.64)$ and twenty asked for at least one information or explanation $(M=2.15, \max =7, S D=2.01)$. Thus, argumentative texts promote interactions between fifth graders.

With regard to the relation between the summarizer's competence and listener's learning, we conducted multilevel analyses, and built the same two-level model as for study 1. Again, the predicted interaction between resource interdependence and summarizer's competence was significant. As in study 1 , we conducted the same analysis using robust modeling [78]. Results showed a unilateral p-value for the main interaction lower than 0.05 for pupils' response as a listener, $b=-0.24, d f=54, t=-2.33, p=0.02$, and $R^{2}=0.08$, indicating that information distribution moderated the effect of the summarizer's competence. As illustrated in Figure 2, the relationship between the summarizer's competence and learning was positive when pupils worked on complementary information $(b=0.11)$ and negative when they worked on identical information $(b=-0.13)$.

Study 2 replicated the predicted dual effect of partners' competence. The expected constructive relation between partners in cooperative learning was only found when pupils worked with complementary information. When pupils worked on identical information, the more their partner was competent, the less they performed.

It is important to note that the theoretical rationale underlining the hypotheses relied on previous research showing that compared with working on complementary information, working on identical information elicited more evaluative pressure [48], more negative reactions ([29], study 1), more perceived competence threat ([29], study 2), and more perceived competition ([50], pilot experiment), whereas working on complementary information reinforced students' cooperation ([29], study 1). Nevertheless, the quality of the relationship between partners was not investigated in study 2. Given the specific age group studied in the present research (elementary school pupils), it is important to assess whether information distribution yielded similar relational effects at elementary school. Thus, we conducted an additional study in order to test the hypothesis that working on identical information elicits perceptions of lower cooperation (here, mutual learning) and higher competitive social comparison than working on complementary information. 


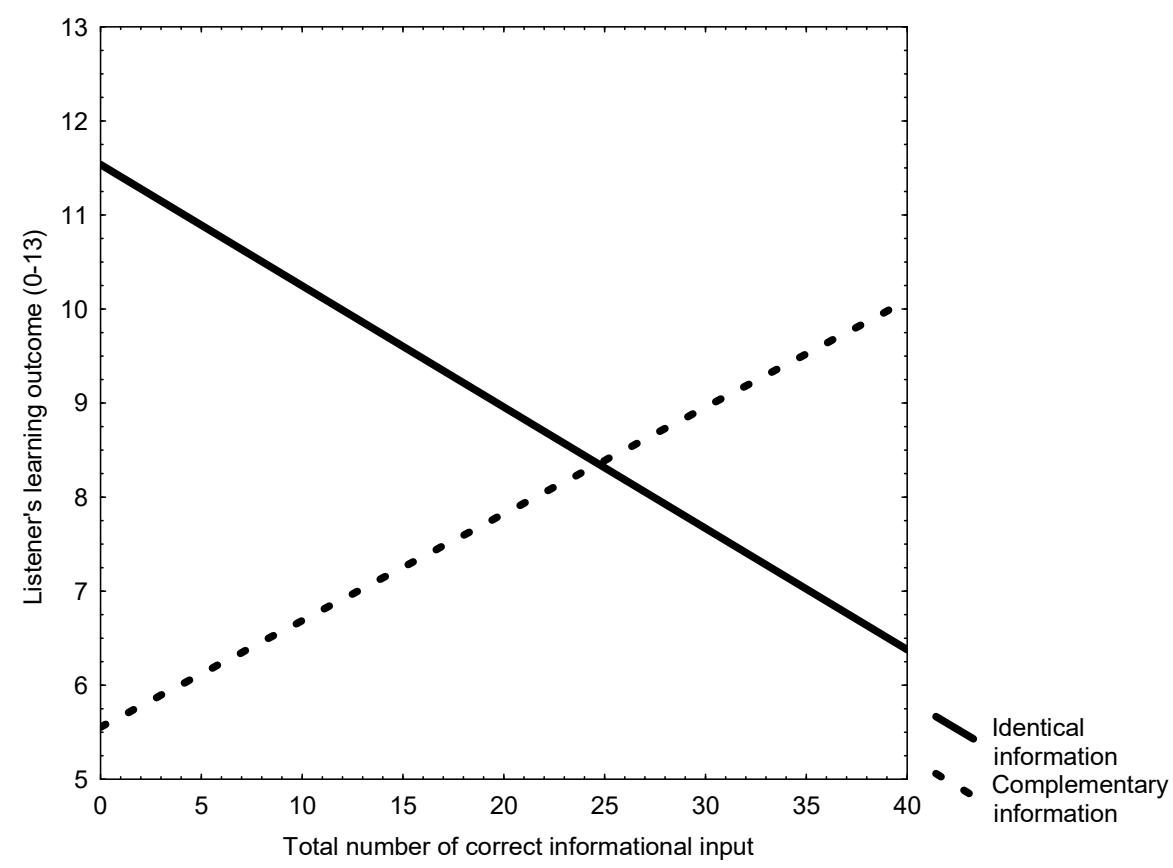

Figure 2. Relationship between partner's competence and listeners' learning in the two interdependence conditions (study 2).

\section{Study 3}

\subsection{Materials and Methods}

\subsubsection{Participants}

Forty-four pupils from two classes, regularly attending grade 5 in a Swiss Frenchspeaking school and aged from 9.92 to 11.68 years $(M=10.74, S D=0.35), 21$ boys and 23 girls, participated in the study. As in previous studies, pupils worked on dyads for one session. Twenty-two pupils worked with complementary information and 22 worked with identical information. Their regular teacher composed the dyads so that the level in French was relatively equivalent inside the dyad and that pupils could work well together (no "enemies" together).

\subsubsection{Procedure}

For each class, half of the dyads were randomly assigned to one of the two experimental conditions manipulating information distribution (resource interdependence: independence vs. positive resource interdependence). This study followed the same procedure as far as working on texts is concerned.

\subsubsection{Materials}

We used the same material (two argumentative texts with a lexicon) as for study 2.

\subsubsection{Independent Variables}

As in previous studies, students worked either on identical or on complementary information and played a summarizer role for one text and a listener role for the other text.

\subsubsection{Dependent Variable}

- Perceived cooperation-mutual learning: Students answered two questions on a fourpoint scale from 1 (Not true) to 4 (Totally true): "I've learned something thanks to my partner" and "My partner has learned something thanks to me". We computed the mean score of the two items for each student $(r=0.79)$.

- Perceived competitive social comparison: We considered that it would be uncomfortable for young students to admit some competitive social comparison when the 
experimenter asked to work cooperatively. To address this problem, we introduced a questionnaire saying that we had proposed the same activity to other fifth grade classrooms and recorded the answer of those pupils. We asked the pupils to indicate to which extent they felt the same. Sentences were proposed in the affirmative form and pupils had to indicate whether the same applied to them on a four-point scale ranging from 1 (very rarely) to 4 (very often). We proposed six items, derived from performance-approach and performance-avoidance goals, as both have been shown to be related to competition [79]: "Some pupils wondered how to appear good"; "Some pupils tried to be better than their partner"; "Some pupils wanted to compare themselves with their partner"; "Some pupils were afraid to be less strong then their partner"; "Some pupils were afraid not to explain well information"; "some pupils wondered whether they managed well". When answering the questionnaire, we separated the two pupils composing the same dyad, and read aloud the questions in order to be sure that pupils understood them. We computed the mean score of the six items for each pupil $(\alpha=0.54)$.

\subsection{Results and Discussion}

The perception of cooperation and competitive social comparison are independent, $r=0.16, p=0.31$. As pupils learned in dyads, data are not independent, and therefore we built a two-level model with pupils nested in dyads.

Students reported that they perceived more cooperation when they worked on complementary information $(M=3.02, S D=0.87)$ than on identical information $(M=2.40$, $S D=0.95), b=0.31, d f=40, t=2.27, p=0.03, R^{2}=0.11$. In contrast, participants working on identical information reported more competitive social comparison $(M=2.08, S D=0.40)$ compared to those working on complementary information $(M=1.78, S D=0.55), b=-0.15$, $d f=40, t=-2.07, p=0.04, R^{2}=0.09$.

The third experiment supported the hypothesis that overall working on identical information elicits perceptions of lower cooperation and higher competitive social comparison than working on complementary information. Thus, it seems that working on identical information may reduce perceived cooperation and stress competitive social comparison more than working on complementary information, even for elementary school children.

\section{General Discussion}

The very principle of cooperative learning consists in leading students and pupils to help each other with a view to learning together, and in creating a context in which mutual support is favored through positive interdependence. Therefore, in cooperative learning, the partners' competence should be a source of informational support and result in promoting learning outcomes. Nevertheless, research on the effect of information distribution on students' learning in cooperative dyads at university revealed that, even in a cooperative context, working on identical information may elicit competitive social comparison between peers. In particular, and this was the starting point of the present research, the logical positive relationship between partner's competence and students ${ }^{\prime}$ learning appeared when they worked on complementary information; when they worked on identical information, however, the partner's competence yielded the paradoxical effect of negatively predicting the students' learning outcomes. These results were found both with perceived partner's competence [29] and with the actual (manipulated via the quality of informational input) partner's competence [30]. Research on the pervasive presence of neo-liberal, competitive values in Western societies $[26,80]$ has led to the interpretation of this effect by considering that students socialized in a competitive society and that the educational system may switch very easily to a competitive mode as soon as focus on social comparison is salient in the task-as is the case for working on identical informationdespite cooperative instruction [81]. The present research studied the generality of this interpretation by testing that, if it is true that competitive societal values have permeated 
the educational system [23], the paradoxical results described above should be likely to appear from the level of elementary school.

We tested the relationship between partners' competence (assessed by the quality of informational input on the text they were in charge to summarize) and the partners' learning outcomes for this text in two studies conducted with fourth graders (study 1) and fifth graders (study 2). In both studies, we found an interaction pattern indicating that information distribution moderated the relationship between the summarizer's competence and the listeners' learning outcomes. This interaction pattern has the same shape as the effect obtained by [29] with university students (see Figures 1 and 2), and in the present experiments, it was observed when pupils worked both on encyclopedic texts (study 1) and on argumentative texts (study 2). In line with our hypothesis, partner's competence was positively related to pupils' learning outcomes when they worked on complementary information, whereas this relationship was negative when they worked on identical information. In sum, the results of both studies underlined that even when cooperative learning is accurately implemented, even in elementary school, an element that favors focus on social comparison-like in this case working on identical informationmay render the partner's competence paradoxically detrimental for learning outcomes. Results regarding students' perception in study 3 supported the hypothesized information distribution properties: Students reported more mutual learning when they worked on complementary information whereas they reported a more competitive social comparison when they worked on identical information. Overall, these results underline that the dual effect of partners' competence may take place from elementary school.

In sum, we propose that the logical positive relationship between the partner's competence and students' learning appeared when they worked on complementary information for two intertwined reasons. On one hand, because each partner accesses different parts, the possibility of social comparison is weak. On the other hand, working cooperatively on complementary information creates an informational dependence because students must rely on what their partner gives them; thus, the reciprocal informational dependence renders the partner's quality of informational input crucial.

In contrast, threatening social comparison may explain the negative impact of partner's competence when working on identical information. When the situation activates social comparison, the partner's competence may elicit a potential threat to self-evaluation. Thus, when working on the same information, partner's performance may become a standard against which students can evaluate their own performance. Such a concern about relative performance has been shown to consume attentional resources because of ruminative thoughts about self-evaluation [82]. The more competent the partner, the more students may be concerned about their own performance. This distraction may interfere with complex information processing, and reduce learning from text. When the partner's competence is low, pressure to attain the same standard is weaker, and students may feel safer, with no intrusive thoughts distracting them from studying and discussing the text.

In addition, students may be guided by strategic information sharing and use in a situation perceived as competitive [83]. When a threatening social comparison is present, students may refrain from asking for information they need for fear of appearing incompetent or clarifying the information the partner needs in order to keep a competitive advantage. Moreover, the threatening social comparison that emerges when working on identical information may orient students toward competitive performance goals. Performance goal orientation may render the interaction with others less constructive [84] and enhance the willingness to exploit the partner's knowledge [85]. Of course, these are speculations and future research should design experiments that may directly test these ideas.

The small number of participants and dyads is obviously a limitation of present studies, which requires caution in the estimation of variance. The three studies were done with convenience samples and at that time, it was not possible to run more classes. Nevertheless, it should be noted that in both studies, the predicted interaction pattern was 
observed, and that this was the same interaction observed by [29] with a sample of adults. It should also be reminded that the effects have been tested with different types of texts (encyclopedic and argumentative texts) and two different grades (grades 4 and 5), which speaks to the external validity of the present results. In other words, the limitation due to the small size of the samples is mitigated by the replication of the predicted effect.

A second limitation is that the present experiments were conducted outside the regular classroom setting, which might question the study's external validity. However, even if variations could be expected between experimental and in-classroom settings, with specific dynamics that depend on the specific relation with peers and teacher in regular classes, Marshall and Weinstein [51] pointed out that working on the same task in regular classrooms elicits the same social comparison of abilities that we observed in the present study. Moreover, studies conducted at university revealed the same pattern of results for a single non-class session $[29,36,50]$ and regular workshop sessions [30].

A third limitation is that we did not test mediators. A reliable measure of such concerns with young pupils represents a challenge. In the present research, we relied upon the already known result that resource independence triggers competitive social comparison and positive resource interdependence attenuates it (e.g., [50]) to study the effect of information distribution on the relationship between partners' competence and pupil's learning. Furthermore, our third study confirms that, among our population of young children, information distribution has the same effect on social comparison as that described in the previous research with adults (resource independence elicits a competitive social comparison whereas resource interdependence reinforces pupils' cooperation). As elementary students could feel uncomfortable reporting competition while being asked to cooperate, we decided to conduct the third study as a separate study to investigate the information distribution effect on social comparison. However, a mediational analysis with a reliable measure of competitive social comparison concerns would represent an interesting addition from future studies.

\section{Conclusions}

These studies contribute to cooperative learning in two ways. First, they indicate that it is possible that competitive goals permeate the whole educational system, and that learners may feel threatened by their partner's competence, with detrimental effects on learning outcomes, already at the level of elementary school, even when cooperative learning instruction is implemented. Our results suggest that as soon as students can compare each other (when they work on identical information), partner's competence may become detrimental for cooperative learning. Future research may address more directly how threatening social comparisons intervene, and may investigate more generally how the promotion of self-enhancement values such as merit, social recognition, and power may hinder the benefits of cooperative learning; and how, on the contrary, promoting self-transcendence values of universalism and benevolence [80] may counteract these detrimental effects.

Second, the present results contribute to stress how important it is to reflect on the way cooperative learning is structured. The two methods manipulated in these studies varied only on one dimension, namely resource interdependence (working either on identical or on complementary information). However, results indicate that the mere fact of reading the same text, with its potential to generate a focus on social comparison [50], led the partner's competence to yield a detrimental effect on learning outcomes. This implies that it is important to reduce a competence threat when pupils work on identical information so that they can benefit from their partner's competence [54]. Preparing students to cooperate could be a useful preliminary step, so that they learn how to cooperate for learning $[47,86]$.

Our results point out that subtle elements of the situation are sufficient to turn constructive interactions into a competence struggle. We hope that this work may orient future research to increase attention to the way cooperative learning is structured, which may influence its effectiveness. 
Author Contributions: Conceptualization, C.B. and F.B.; Methodology, C.B. and F.B.; Analysis, J.C. and C.B.; Writing-Original, C.B. and A.D.; Writing-Review \& Editing, C.B., A.D., J.C. and F.B. All authors have read and agreed to the published version of the manuscript.

Funding: This research received no external funding.

Institutional Review Board Statement: At the time of the studies, no approval was needed in Switzerland to conduct non-medical research on human subjects. As stated by the Federal Administration of the Swiss Confederation (https:/ / www.bag.admin.ch/bag/en/home/medizin-undforschung/forschung-am-menschen/entstehung-humanforschungsgesetz.html), the law relating to research on human subjects (i.e., constitutional article $n^{\circ} 118 b$ ) came into effect in 1 January 2014. Given this legislation, the present research project was not submitted to any research ethics board. Each study was approved by the research commission in schools in partnership with the university and Genevan department of public instruction

Informed Consent Statement: As the participants were children, we asked for permission to (1) the head of school, (2) the teachers.

Data Availability Statement: The data presented in this study are available on request from the corresponding author. The data are not publicly available due to the confidential information.

Conflicts of Interest: The authors declare no conflict of interest.

Ethics Statement: According to the regulations of the country where the study was carried out, approval from an ethical board was not required when data were collected.

\section{References}

1. Gillies, R.M. Cooperative group work. In The Encyclopedia of Child and Adolescent Development; Hupp, S., Jewell, J.D., Eds.; John Wiley Sons: Hoboken, NJ, USA, 2020; pp. 1-11.

2. Gillies, R.M. Structuring co-operative learning experiences in primary schools. In Co-operative Learning: The Social and Intellectual Outcomes of Learning in Groups; Gillies, R.M., Ashman, A.F., Eds.; Routledge: New York, NY, USA, 2003; pp. $35-53$.

3. Johnson, D.W.; Johnson, R.T.; Johnson Holubec, E. Cooperation in the Classroom (Revised); Interaction Book Company: Minneapolis, MN, USA, 1998.

4. Kutnick, P.; Ota, C.; Berdondini, L. Improving the effects of group working in classrooms with young school-aged children: Facilitating attainment, interaction and classroom activity. Learn. Instr. 2008, 18, 83-95. [CrossRef]

5. Rohrbeck, C.A.; Ginsburg-Block, M.D.; Fantuzzo, J.W.; Miller, T.R. Peer-assisted learning interventions with elementary school students: A meta-analytic review. J. Educ. Psychol. 2003, 95, 240-257. [CrossRef]

6. Stevens, R.J.; Slavin, R.E. The cooperative elementary school: Effects on students' achievement, attitudes, and social relations. Am. Educ. Res. J. 1995, 32, 321-351. [CrossRef]

7. Gillies, R.M. The effect of cooperative learning on junior high school students during small group learning. Learn. Instr. 2004, 14, 197-213. [CrossRef]

8. Kutnick, P.; Blatchford, P.; Clark, H.; MacIntyre, H.; Baines, E. Teachers' understandings of the relationship between within-class (pupil) grouping and learning in secondary schools. Educ. Res. 2005, 47, 1-24. [CrossRef]

9. Roseth, C.J.; Johnson, D.W.; Johnson, R.T. Promoting early adolescents' achievement and peer relationships: The effects of cooperative, competitive, and individualistic goal structures. Psychol. Bull. 2008, 134, 223-246. [CrossRef]

10. Johnson, D.W.; Johnson, R.T. Social interdependence theory and university instruction: Theory into practice. Swiss J. Psychol. 2002, 61, 119-129. [CrossRef]

11. Johnson, D.W.; Johnson, R.T.; Smith, K. The state of cooperative learning in postsecondary and professional settings. Educ. Psychol. Rev. 2007, 19, 15-29. [CrossRef]

12. Johnson, D.W.; Johnson, R.T.; Smith, K.A. Cooperative learning: Improving university instruction by basing practice on validated theory. J. Excell. Coll. Teach. 2014, 25, 85-118.

13. Vazin, T.; Reile, P. Collaborative learning: Maximizing students' potential for success. In Handbook of the Teaching of Psychology; Buskist, W., Davis, S.F., Eds.; Blackwell Publishing: Malden, MA, USA, 2006; pp. 65-69.

14. Tolmie, A.K.; Topping, K.J.; Christie, D.; Donaldson, C.; Howe, C.; Jessiman, E.; Livingston, K.; Thurston, A. Social effects of collaborative learning in primary schools. Learn. Instr. 2010, 20, 177-191. [CrossRef]

15. Gillies, R.M. Cooperative Learning: Integrating Theory and Practice, 1st ed.; SAGE Publications: Los Angeles, CA, USA, 2007.

16. Gillies, R.M. Collaborative Learning: Developments in Research and Practice; Nova Science Publishers: New York, NY, USA, 2015; pp. 1-15.

17. Gillies, R.M. Cooperative learning: Review of research and practice. Aust. J. Teach. Educ. 2016, 41, 39-54. [CrossRef]

18. Johnson, D.W.; Johnson, R.T. An educational psychology success story: Social interdependence theory and cooperative learning. Educ. Res. 2009, 38, 365-379. [CrossRef] 
19. Slavin, R.E. Instruction based on cooperative learning. In Handbook of Research on Learning and Instruction; Mayer, R., Ed.; Taylor and Francis: London, UK, 2011; pp. 344-360.

20. Slavin, R.E. Cooperative learning and academic achievement: Why does groupwork work? An. Psicol. 2014, 30, 785-791. [CrossRef]

21. Topping, K.J.; Buchs, C.; Duran, D.; Van Keer, H. Effective Peer Learning: From Principles to Practical Implementation; Routledge: London, UK, 2017.

22. Hattie, J. Visible Learning: A synthesis of over 800 Meta-Analyses Relating to Achievement; Routledge: New York, NY, USA, 2009.

23. Butera, F.; Świątkowski, W.; Dompnier, B. Competition in education. In The Oxford Handbook on the Psychology of Competition; Garcia, S., Tor, A., Elliot, A., Eds.; Oxford University Press: New York, NY, USA, in press.

24. Harackiewicz, J.M.; Barron, K.E.; Elliot, A.J. Rethinking achievement goals: When are they adaptive for college students and why? Educ. Psychol. 1998, 33, 1-21. [CrossRef]

25. Bettache, K.; Chiu, C.Y. The invisible hand is an ideology: Toward a social psychology of neoliberalism. J. Soc. Issues 2019, 75, 8-19. [CrossRef]

26. Kasser, T.; Cohn, S.; Kanner, A.D.; Ryan, R.M. Some costs of American corporate capitalism: A psychological exploration of value and goal conflicts. Psychol. Inq. 2007, 18, 1-22. [CrossRef]

27. Butera, F.; Batruch, A.; Autin, F.; Mugny, G.; Quiamzade, A.; Pulfrey, C. Teaching as social influence: Empowering teachers to become agents of social change. Soc. Issues Policy Rev. 2021, 15, 323-355. [CrossRef]

28. Keramati, M.R.; Gillies, R.M. Constraints of Cooperative Learning in University Classrooms: A Qualitative Study in Iran and Australia. Iran. J. Comp. Educ. 2021, 4, 958-972. [CrossRef]

29. Buchs, C.; Butera, F.; Mugny, G. Resource interdependence, student interactions and performance in cooperative learning. Educ. Psychol. 2004, 24, 291-314. [CrossRef]

30. Buchs, C.; Butera, F. Is a partner's competence threatening during dyadic cooperative work? It depends on resource interdependence. Eur. J. Psychol. Educ. 2009, 24, 145-154. [CrossRef]

31. Sharan, S. Handbook of Cooperative Learning Methods; Greenwood Publishing Group: Westport, CT, USA, 1999.

32. Butera, F.; Buchs, C. Social Interdependence and the promotion of cooperative learning. In Social Psychology in Action; Sassenberg, K., Vliek, M., Eds.; Springer Nature: Cham, Switzerland, 2019; pp. 111-127.

33. Sharan, Y. Cooperative learning for academic and social gains: Valued pedagogy problematic practice. Eur. J. Educ. 2010, 45, 300-310. [CrossRef]

34. Deutsch, M. Cooperation and trust: Some theoretical notes. In Nebraska Symposium on Motivation; Jones, M.R., Ed.; University of Nebraska Press: Lincoln, NE, USA, 1962; pp. 275-319.

35. Johnson, D.W.; Johnson, R.T. New developments in social interdependence theory. Genet. Soc. Gen. Psychol. Monogr. 2005, 131, 285-358. [CrossRef] [PubMed]

36. Buchs, C.; Butera, F. Socio-cognitive conflict and the role of student interaction in learning. New Rev. Soc. Psychol. 2004, 3, 80-87.

37. Roussel, P.; Elliot, A.J.; Feltman, R. The influence of achievement goals and social goals on help-seeking from peers in an academic context. Learn. Instr. 2011, 21, 394-402. [CrossRef]

38. Johnson, D.W.; Johnson, R.T. Cooperation and Competition, Theory and Research; Interaction Book Company: Minneapolis, MN, USA, 1989.

39. Slavin, R.E. When does cooperative learning increase student achievement? Psychol. Bull. 1983, 94, 429-445. [CrossRef]

40. Barron, K.; Harackiewicz, J.M. Achievement goals and optimal motivation: A multiple goals approach. In Intrinsic and Extrinsic Motivation: The Search for Optimal Motivation and Performance; Harackiewicz, J.M., Ed.; Academic Press: San Diego, CA, USA, 2000; pp. 229-254.

41. Darnon, C.; Dompnier, B.; Delmas, F.; Pulfrey, C.; Butera, F. Achievement goal promotion at university: Social desirability and social utility of mastery and performance goals. J. Pers. Soc. Psychol. 2009, 96, 119-134. [CrossRef]

42. Urdan, T.; Turner, J.C. Competence motivation in the classroom. In Handbook of Competence and Motivation; Elliot, A.J., Dweck, C.S., Eds.; Guilford Publications: New York, NY, USA, 2005; pp. 297-317.

43. Pulfrey, C.; Buchs, C.; Butera, F. Why grades engender performance-avoidance goals: The mediating role of autonomous motivation. J. Educ. Psychol. 2011, 103, 683-700. [CrossRef]

44. OECD. Education at a Glance 2009: OECD Indicators. Available online: http://www.oecd.org/edu/eag2009 (accessed on 3 February 2012).

45. European Commission. 2011 ECTS User's Guide. Available online: http:/ / ec.europa.eu/education/lifelong-learning-policy/ doc/ects/guide_en.pdf (accessed on 3 February 2012).

46. Burleigh, T.J.; Meegan, D.V. Risky prospects and risk aversion tendencies: Does competition in the classroom depend on grading practices and knowledge of peer-status? Soc. Psychol. Educ. 2018, 21, 323-335. [CrossRef]

47. Buchs, C.; Gilles, I.; Antonietti, J.-P.; Butera, F. Why students need training to cooperate: A test in statistics learning at university. Educ. Psychol. 2016, 36, 956-974. [CrossRef]

48. Lambiotte, J.G.; Dansereau, D.F.; O’Donnell, A.M.; Young, M.D.; Skaggs, L.P.; Hall, R.H.; Rocklin, T.R. Manipulating cooperative scripts for teaching and learning. J. Educ. Psychol. 1987, 79, 424-430. [CrossRef]

49. Roseth, C.J.; Lee, Y.K.; Saltarelli, W.A. Reconsidering jigsaw social psychology: Longitudinal effects on social interdependence, sociocognitive conflict regulation, motivation, and achievement. J. Educ. Psychol. 2019, 111, 149-169. [CrossRef] 
50. Buchs, C.; Pulfrey, C.; Gabarrot, F.; Butera, F. Competitive conflict regulation and informational dependence in peer learning. Eur. J. Soc. Psychol. 2010, 40, 418-435. [CrossRef]

51. Marshall, H.H.; Weinstein, R.S. Classroom factors affecting students' self-evaluations: An interactional model. Rev. Educ. Res. 1984, 54, 301-325. [CrossRef]

52. Butera, F.; Darnon, C. Competence assessment, social comparison and conflict regulation. In Handbook of Competence and Motivation, 2nd ed.; Theory and Application; Elliot, A., Dweck, C., Yaeger, D., Eds.; Guilford Press: New York, NY, USA, 2017 ; pp. 192-213.

53. Huguet, P.; Dumas, F.; Monteil, J.M.; Genestoux, N. Social comparison choices in the classroom: Further evidence for students' upward comparison tendency and its beneficial impact on performance. Eur. J. Soc. Psychol. 2001, 34, 557-578. [CrossRef]

54. Buchs, C.; Filippou, D.; Pulfrey, C. Reducing Threat in Cooperative Learning: The Role of Decentering. Int. Rev. Soc. Psychol. 2018, 31, 1-7. [CrossRef]

55. Chan, M.E. Antecedents of instrumental interpersonal help-seeking: An integrative review. Appl. Psychol. Int. Rev. 2013, 62, 571-596. [CrossRef]

56. Mosatche, H.S.; Bragonier, P. An observational study of social comparison in preschoolers. Child Dev. 1981, 52, 376-378. [CrossRef]

57. Nicholls, J.G.; Miller, A.T. The differentiation of the concepts of difficulty and ability. Child Dev. 1983, 54, 951-959. [CrossRef]

58. Stipek, D.; Mac Iver, D. Developmental change in children's assessment of intellectual competence. Child Dev. 1989, 60, 521-538. [CrossRef]

59. Dijkstra, P.; Kuyper, H.; van der Werf, G.; Buunk, A.P.; van der Zee, Y. Social comparison in the classroom: A review. Rev. Educ. Res. 2008, 78, 828-879. [CrossRef]

60. Butler, R. Age trends in the use of social and temporal comparison for self-evaluation: Examination of a novel developmental hypothesis. Child Dev. 1998, 69, 1054-1073. [CrossRef]

61. Rhodes, M.; Brickman, D. Preschoolers' responses to social comparisons involving relative failure. Psychol. Sci. 2008, 19, 968-972. [CrossRef] [PubMed]

62. Ruble, D.N.; Eisenberg, R.; Higgins, E.T. Developmental changes in achievement evaluation: Motivational implications of self-other differences. Child Dev. 1994, 65, 1095-1110. [CrossRef] [PubMed]

63. Butler, R.; Ruzany, N. Age and socialization effects on the development of social comparison motives and normative ability assessment in kibbutz and urban children. Child Dev. 1993, 64, 532-543. [CrossRef]

64. Pepitone, E.A. Comparison behavior in elementary school children. Am. Educ. Res. J. 1972, 9, 45-63. [CrossRef]

65. Gürel, Ç.; Brummelman, E.; Sedikides, C.; Overbeek, G. Better than my past self: Temporal comparison raises children's pride without triggering superiority goals. J. Exp. Psychol. Gen. 2020, 149, 1554-1566. [CrossRef]

66. Lapan, C.; Boseovski, J.J. When peer performance matters: Effects of expertise and traits on children's self-evaluations after social comparison. Child Dev. 2017, 88, 1860-1872. [CrossRef]

67. Wehrens, M.J.P.W.; Buunk, A.P.; Lubbers, M.J.; Dijkstra, P.; Kuyper, H.; van der Werf, G.P.C. The relationship between affective response to social comparison and academic performance in high school. Contemp. Educ. Psychol. 2010, 35, 203-214. [CrossRef]

68. Midgley, C.; Anderman, E.M.; Hicks, L. Differences between elementary and middle school teachers and students: A goal theory approach. J. Early Adolesc. 1995, 15, 90-113. [CrossRef]

69. Midgley, C.; Eccles, J.S.; Feldlaufer, H. Classroom environment and the transition to junior high school. In Educational Environments: Evaluation, Antecedents and Consequences; Fraser, B.J., Walberg, H.J., Eds.; Pergamon Press Inc.: Oxford, UK, 1991 ; pp. 113-140.

70. Meece, J.L.; Anderman, E.M.; Anderman, L.H. Classroom goal structure, student motivation, and academic achievement. Annu. Rev. Psychol. 2006, 57, 487-503. [CrossRef]

71. Autin, F.; Batruch, A.; Butera, F. The function of selection of assessment leads evaluators to artificially create the social class achievement gap. J. Educ. Psychol. 2019, 111, 717-735. [CrossRef]

72. Batruch, A.; Autin, F.; Bataillard, F.; Butera, F. School selection and the social class divide: How tracking contributes to the reproduction of inequalities. Pers. Soc. Psychol. Bull. 2019, 45, 477-490. [CrossRef]

73. Wentzel, K.R.; Baker, S.A.; Russell, S.L. Young adolescents' perceptions of teachers' and peers' goals as predictors of social and academic goal pursuit. Appl. Psychol. Int. Rev. 2012, 61, 605-633. [CrossRef]

74. Patrick, H.; Anderman, L.H.; Allison, M.R.; Edelin, K.C.; Midgley, C. Teachers' communication of goal orientations in four fifth-grade classrooms. Elem. Sch. J. 2001, 102, 35-58. [CrossRef]

75. Buchs, C.; Gilles, I.; Dutrévis, M.; Butera, F. Pressure to cooperate: Is positive reward interdependence really needed in cooperative learning? Br. J. Educ. Psychol. 2011, 81, 135-146. [CrossRef] [PubMed]

76. O'Donnell, A.M. Structuring dyadic interaction through scripted cooperation. In Cognitive Perspectives on Peer Learning, the Rutgers Invitational Symposium on Education Series; O’Donnell, A.M., King, A., Eds.; Lawrence Erlbaum Associates: Mahwah, NJ, USA, 1999; pp. 179-196.

77. O'Donnell, A.M.; Dansereau, D.F. Scripted cooperation in student dyads: A method for analyzing and enhancing academic learning and performance. In Interaction in Cooperative Groups: The Theoretical Anatomy of Group Learning; Hertz-Lazarowitz, R., Miller, N., Eds.; Cambridge Press: New York, NY, USA, 1995; pp. 120-141.

78. Courvoisier, D.; Renaud, O. Robust analysis of the central tendency, simple and multiple regression and ANOVA: A step by step tutorial. Int. J. Psycholo. Res. 2010, 3, 78-87. [CrossRef]

79. Murayama, K.; Elliot, A.J. The competition-performance relation: A meta-analytic review and test of the opposing processes model of competition and performance. Psychol. Bull. 2012, 138, 1035-1070. [CrossRef] [PubMed] 
80. Schwartz, S.H. Cultural and individual value correlates of capitalism: A comparative analysis. Psychol. Inq. 2007, 18, 52-57. [CrossRef]

81. Buchs, C.; Butera, F. Cooperative learning and social skills development. In Collaborative Learning: Developments in Research and Practice; Gillies, R., Ed.; Nova Science: New York, NY, USA, 2015; pp. 201-217.

82. Muller, D.; Butera, F. The focusing effect of self-evaluation threat in coaction and social comparison. J. Pers. Soc. Psychol. 2007, 2, 194-211. [CrossRef]

83. Toma, C.; Butera, F. Hidden Profiles and Concealed Information: Strategic Information Sharing and Use in Group Decision Making. Pers. Soc. Psychol. Bull. 2009, 35, 793-806. [CrossRef]

84. Darnon, C.; Dompnier, B.; Poortvliet, P.M. Achievement goals in educational contexts: A social psychology perspective. Soc. Pers. Psychol. Compass 2012, 6, 760-771. [CrossRef]

85. Sommet, N.; Nguyen, D.; Fahrni, K.; Jobin, M.; Nguyen, H.P.; Sehaqui, H.; Butera, F. When and why performance goals predict exploitation behaviors: An achievement goal complex analysis of the selection function of assessment. Motiv. Emot. 2019, 43, 266-284. [CrossRef]

86. Sharan, Y. Learning to cooperate for cooperative learning. An. Psicol. 2014, 30, 802-807. [CrossRef] 